\title{
Correction to: The Effects of Hispanic Immigrant Mother's Resiliency on Children's Dietary Adjustment
}

\author{
Elizabeth Villegas ${ }^{1} \cdot$ Angela Wiley $^{2} \cdot$ Bridget Hannon $^{3} \cdot$ Margarita Teran-Garcia $^{1,3,4} \cdot$ Amber Hammons $^{5}$
}

Published online: 3 December 2018

(c) Springer Science+Business Media, LLC, part of Springer Nature 2018

\section{Correction to: Journal of Immigrant and Minority Health https://doi.org/10.1007/s10903-018-0810-x}

The original version of this article unfortunately contained errors in Affiliation 3, Acknowledgement, Table 1 and in the text under Methods section. Also, a Co-corresponding author has to be included in the article.

In affiliation 3, "Department of Nutritional Sciences" should be "Division of Nutritional Sciences."

Dr. Margarita Teran-Garcia is added as a co-corresponding author of this article and the author is also affiliated to "Cooperative Extension, College of Agriculture and Consumer Economics (ACES), University of Illinois, UrbanaChampaign, Urbana, IL, USA."

In Methods section, the first sentence should read as "This study used data from a larger intervention study, Abriendo Caminos, is a multi-state, randomized-controlled, childhood obesity prevention program that is culturally-tailored for Mexican and Puerto Rican families."

The original article can be found online at https://doi.org/10.1007/ s10903-018-0810-x.

Elizabeth Villegas

Eville3@illinois.edu

$\bowtie$ Margarita Teran-Garcia

teranmd@illinois.edu

1 Department of Human Development and Family Studies, University of Illinois Urbana-Champaign, 904 W Nevada St., Urbana, IL, USA

2 Department of Human Development and Family Studies, Auburn University, Auburn, AL, USA

3 Division of Nutritional Sciences, University of Illinois Urbana-Champaign, Urbana, IL, USA

4 Cooperative Extension, College of Agriculture and Consumer Economics (ACES), University of Illinois, Urbana-Champaign, Urbana, IL, USA

5 Department of Family and Consumer Sciences, California State University, Fresno, Fresno, CA, USA
In Table 1, the unit of measurement $\left(\mathrm{kg} / \mathrm{cm}^{2}\right)$ was missed out for Mother's BMI. Also, the text percentile is missed in the table note. Hence, the table note should read as "There are seven missing child BMI percentile measurements."

The correct acknowledgement section is given below:

Acknowledgements This research project is supported by the Agriculture and Food Research Initiative Competitive (AFRI) Grant No. 2015-68001-23248 from the USDA National Institute of Food and Agriculture (NIFA) under the Childhood Obesity Prevention Challenge Area to Cooperative Extension and the Department of Human Development and Family Studies at the University of Illinois, UrbanaChampaign. This initiative also supports Elizabeth Villegas Graduate Fellowship at the University of Illinois. Any opinions, findings, conclusions, or recommendations expressed in this publication are those of the author(s) and do not necessarily reflect the view of the U.S. Department of Agriculture. The authors acknowledge undergraduate research members of the Abriendo Caminos Research Lab team in the Department of Human Development and Family Studies at UIUC, and in the Department of Child and Family Science at California State University, Fresno, who contributed to this project through data collection and program implementation. We gratefully acknowledge our participants who made this study possible. 